\title{
Output Feedback Adaptive Sliding Mode Control Design for a Plate Heat Exchanger
}

\author{
Shibly Ahmed AL-Samarraie \\ Control and Systems Eng. Dep. \\ University of Technology, Baghdad, IRAQ \\ 60132@uotechnology.edu.iq
}

\author{
Luma F. Ali \\ Mechanical Eng. Dep. \\ University of Baghdad, Baghdad, IRAQ \\ luma.f@coeng.uobaghdad.edu.iq
}

\author{
Received: 17-Oct.-2018 Revised: 18-Nov.-2018 Accepted: 20-Dec.-2018 \\ http://doi.org/10.29194/NJES.21040549
}

\begin{abstract}
The heat exchanger is a device used to transfer heat energy between two fluids, hot and cold. In this work, an output feedback adaptive sliding mode controller is designed to control the temperature of the outlet cold water for plate heat exchanger. The measurement of the outlet cold temperature is the only information required. Hence, a sliding mode differentiator was designed to estimate the time derivative of outlet hot water temperature, which it is needed for constructing a sliding variable. The discontinuous gain value of the sliding mode controller is adapted according to a certain adaptation law. Two constraints which imposed on the volumetric flow rate of outlet cold (control input) were considered within the rules of the proposed adaptation law in this work. These are the control input is a positive quantity, and it limited by a maximum value. The maximum allowable desired outlet cold water has been estimated as function of heat exchanger parameters and maximum control input. The simulation results demonstrate the performance of the proposed adaptive sliding mode control where the outlet cold water was forced to follow desired temperature equal to $45^{\circ}$. Additionally, the robustness of the proposed controller was tested for the case where the cold water inlet temperature is not constant, and also for the case of heat exchanger parameters uncertainty. The results were revealed the robustness of the proposed controller.
\end{abstract}

Keywords: Plate Heat Exchanger, Adaptive sliding mode control, Sliding mode differentiator.

\section{Introduction}

In the modern industrial engineering, plate heat exchanger takes an important role. It is the glossary device in controlling heat output from heating substation, especially for large scale zone heating system.

For plate heat exchanger processes, powerful control of plate heat exchanger is an indicator problem to improve its dynamic performance. To control the heat outputs to secondary networks in large scale district heating systems, plate heat exchangers are glossary components. By designing a powerful control for indicated heat exchanger, dynamic response will be developed and increases control system stability.

Several techniques have been developed in the literature to control of heat exchangers. For instance in [1], the robust model predictive control (MPC) with integral action was designed. To improve control functioning, two-degrees-offreedom loop-shaping controller was worked out by [2] for plate heat exchanger depending on state space model. The control algorithm consists of an on-off type with hysteresis was proposed in [3]. It implemented with a PIC microcontroller and a relay as its actuator. In [4], a dynamic behavior identification of a through-flow heat exchanger was proposed and a self-tuning predictive was designed. The internal model based PID controller proposed in [5] to provide a satisfactory performance for the heat exchanger in both steady state and transient state. A simple bounded positive control system for heat exchangers was proposed by [6]. The controller does not need to feed back the whole state vector and additionally, the positivity and boundedness of the input flow rate was guaranteed. In [7] an approximate inputoutput linearizing feedback and an observer-based uncertainty estimator were used to design robust controller with uncertainty estimation for heat exchanger. The adaptive control with identification of a static behavior of a throughflow heat exchanger for its control was proposed by [8].

Sliding mode control (SMC) is a robust design methodology based on a systematic scheme ensures the attractiveness of a sliding manifold. During sliding motion, the system becomes invariant to system uncertainties and external disturbances. This is known as the invariance property, which represents the main advantage of sliding mode control. Conversely, the main disadvantage is the chattering problem. This can be overcome by suitable selection of the control gain. Of the pioneering method to reduce the dissentious gain and attenuate chattering is the adaptive sliding control (ASMC) method. The ASMC consists of sliding mode controller and adaptive controller [9]. With the use of a sliding mode control system we can reduced the control 
effort by selecting a proper control gain related to the change of system parameters and uncertainty. An ASMC methodology that guarantees a real sliding mode only was proposed by [10]. The sliding mode controller was used by many authors to design robust controller to the heat exchanger system as in [11, 12, \& 13].

The aim of the present work is to control the temperature of the outlet cold water. This consists of design an output state feedback ASMC, and a sliding mode differentiator to estimate the derivative of the outlet cold water.

\section{Plate Heat Exchanger \\ Mathematical Model}

In Fig. (1), schematic diagram of the plate heat exchanger is depicted. It is incorporated of a mound of parallel thin plates which are assembled between heavy end plates. Where heat is exchanged through adjoining plates in the mound, cold and hot water proceed interchangeably between these plates. The control target is to accommodate the outlet cold water temperature, $T_{c o}(t)$, in order to retain this temperature as close as possible to the intended set point temperature.

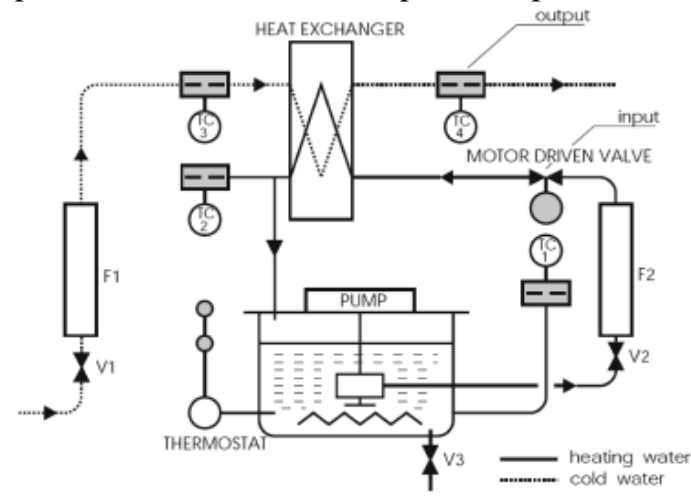

Figure 1: Schematic diagram of the plate heat exchanger [11].

The heat exchanger parameters are as follows; the flow rate $U_{c}$ is the fixed volumetric flow rate of cold water; $V_{c}$ and $V_{h}$ are cold and hot water volumes, respectively.

The inlet cold and hot water temperatures are denoted by $T_{c i}$ and $T_{h i}$ respectively, where they considered fixed. The area of all plates is represented by $A ; U$ is the heat transfer coefficient. The specific heat coefficients $C_{p, h}$ and $C_{p, c}$ are referred to the hot water and the cold water, respectively. Finally $\rho_{h}$ and $\rho_{c}$ are the hot water and the cold water densities coefficients respectively.

For the heat exchanger model, the state variable are $T_{c o}(t)$ and $T_{h o}(t)$, while the volumetric flow rate of the hot water is the control input $u(t)$.

As in reference [11], the plate heat exchanger dynamic model is given by:

$$
\left.\begin{array}{rl}
\dot{T}_{c o}(t)=-k_{1}\left(T_{c o}(t)\right. & \left.-T_{h o}(t)\right) \\
& +\frac{U_{c}}{V_{c}}\left(T_{c i}(t)-T_{c o}(t)\right) \\
\dot{T}_{h o}(t)=-k_{2}\left(T_{h o}(t)-\right. & \left.T_{c o}(t)\right) \\
+\frac{1}{V_{h}}\left(T_{h i}(t)-T_{h o}(t)\right) u(t)
\end{array}\right\}
$$

where;

$k_{1}=U A /\left(C_{p, c} \rho_{c} V_{c}\right)$ and $k_{2}=U A /\left(C_{p, h} \rho_{h} V_{h}\right)$

To this end, define the system states in terms of $x_{1}$ and $x_{2}$;

$x_{1}=T_{c o}(t)$

$\left.x_{2}=T_{h o}(t)\right\}$

Hence, the plate heat exchanger dynamics, in terms of state variables $\left(x_{1}, x_{2}\right)$, is given by;

$$
\left.\begin{array}{rl}
\dot{x}_{1}(t)=- & k_{1}\left(x_{1}(t)-x_{2}(t)\right) \\
+ & \frac{U_{c}}{V_{c}}\left(T_{c i}(t)-x_{1}(t)\right) \\
\dot{x}_{2}(t)=- & k_{2}\left(x_{2}(t)-x_{1}(t)\right) \\
+ & \frac{1}{V_{h}}\left(T_{h i}(t)-x_{2}(t)\right) u(t)
\end{array}\right\}
$$

Additionally, and in order for the heat exchanger model to be more appropriate for control design, let:

$\left.\begin{array}{l}z_{1}=x_{1} \\ z_{2}=\dot{z}_{1}=\dot{x}_{1}\end{array}\right\}$

Eventually, with respect to the new states $\left(z_{1}, z_{2}\right)$ the heat exchanger model becomes;

$$
\left.\begin{array}{rl}
\dot{z}_{1} & =z_{2} \\
\dot{z}_{2} & =a x_{1}+b x_{2}+c(t)+g(x, t) u \\
& =f(t, x)+g(x, t) u
\end{array}\right\}
$$

where;

$$
\begin{aligned}
& a=\left(k_{1}\right)^{2}+2 k_{1} \frac{U_{c}}{V_{c}}+k_{1} k_{2}-\left(\frac{U_{c}}{V_{c}}\right)^{2}, \\
& b=\left(k_{1}\right)^{2}-k_{1} k_{2}-k_{1}\left(\frac{1}{V_{h}}+\frac{U_{c}}{V_{c}}\right) \text {, } \\
& f(x)=a x_{1}+b x_{2}-\left(k_{1} \frac{U_{c}}{V_{c}}+\left(\frac{U_{c}}{V_{c}}\right)^{2}\right) T_{c i}(t) \\
& +k_{1} \frac{1}{V_{h}} T_{h i}+\frac{U_{c}}{V_{c}} \dot{T}_{c i}(t) \\
& \text { and } g(x, t)=k_{1} \frac{1}{V_{h}}\left(T_{h i}(t)-x_{2}\right) \text {. }
\end{aligned}
$$

Note that $g(x, t)>0 \forall x_{2}$, since physically $T_{h i}(t)>T_{h o}(t) \forall t$. Also, this model will be considered uncertain. That is, the model parameters and inputs, $a, b, c(t)$ and $g(x, t)$, are uncertain but bounded by finite values.

In this work, the heat exchanger model is transformed, via Eq. (4) in Eq. (5), to a second order system. In sliding mode control, it is quite simple to derive the system state towards sliding 
manifold. However, for the heat exchanger application, there are two obstacles which prevents from designing the controller as in the usual case. The first obstacle is that the control input is positive only. That means the control action is from one side only, hence; it derive the state to the sliding manifold from one side only. In the other side of the sliding manifold, the attractiveness of the sliding manifold depends on inherent heat exchanger system dynamics. As a result, it is needed, from the control system designer, to prove the siding manifold attractiveness for the open loop. Secondly, the volumetric flow rate of the hot water has a maximum value, which it named, in control theory, as control input saturation. The control design is accordingly semi-global, and again we need to show that when the state initiated outside the control area, it reenter this area, and then the control input direct the state to the sliding manifold.

The heat exchanger model, as given in Eq. (5), will be used in the next section to design a robust control system utilizing the theory of sliding mode control.

\section{Sliding Mode Control}

Physical systems are often subjected to model inaccuracies; these inaccuracies may come from un-modeled or neglected system dynamics, uncertainty in model parameters (i.e. deviation of the system parameters from actual values) and external disturbances. Many challenges will be arising when the physical system is uncertain, i.e., the model is uncertain and subjected to external disturbances. This may lead a non-satisfactory performance or even system instability. For this reason, when a control methodology considers the system uncertainty, it named as robust control. One these robust control methodologies, is the sliding mode control (SMC), which characterized by high simplicity and robustness [14].

\section{Adaptive Sliding Mode Control Law}

For application of sliding mode control, there exist two main obstacles. These are the chattering and large gain of control action. The magnitude of a discontinuous control is responsible of high amplitude of chattering. These two problem, which prevent using the SMC for many applications, can be solved if the discontinues gain is reduced to a minimum admissible value with preserving global or semi-global attractiveness of the sliding manifold.

Here an adaptation law will be utilized to adapt the gain of the SMC at minimum sufficient value. Using this gain, the chattering amplitude will be eliminated or reduced with minimum control effort.
Consider the following sliding mode controller in Eq. (6) with adaptive gain [15]

$u(s, t)=-k(t) \operatorname{sign}(s(x, t))$

where $k(t)$ is the discontinuous gain which computed according to the following; let $\epsilon$ be a small positive constant, then $k(t)$ is determined as follows;

Set the initial value of $\mu$ as $\mu_{\text {initial }}=k$, then;

$\dot{\mu}=\rho *|s(x, t)| * \operatorname{sign}(|s(x, t)|-\epsilon)$

After that $k(t)$ is selected accordingto the following rules;

$k=\left\{\begin{array}{lr}\mu & \text { if } K_{\min }<\mu<K_{\max } \\ K_{\min } & \text { if } \mu \leq K_{\min } \\ K_{\max } & \text { if } \mu \geq K_{\max }\end{array}\right.$

where $\rho>0, \epsilon>0, K_{\text {min }}<k(0)<K_{\text {mix }}$, $K_{\text {min }}$ is the minimum possible value of $k(t)$ and $K_{\max }$ it's maximum possible value.

Equations (7) and (8) represent the adaptation law for the SMC gain, which it has been used in many applications as in $[16,17]$. The adaptation law above will be used in section (5), after certain modification considering that the control action is a positive quantity.

\section{Adoptive Slinding Mode Control Design}

In this section, the adaptive sliding mode control for the plate heat exchanger is designed according to the previous section. In the first design step, the sliding variable is selected as;

$s=e_{2}+\lambda e_{1}, \lambda>0$

where $e_{1}$ and $e_{2}$ are the error functions which are defined by:

$e_{1}=z_{1}-z_{1 r}=T_{c o}(t)-T_{c o r}(t)$

$\left.e_{2}=z_{2}-z_{2 r}=\dot{T}_{c o}(t)-\dot{T}_{c o r}(t)\right\}$

Here $T_{\text {cor }}(t)$ is the desired outlet cold temperature, while $\dot{T}_{c o r}(t)$ is its time derivative.

According to the SMC theory, the control task is to direct the state trajectory (the error state $\left.\left(e_{1}, e_{2}\right)\right)$ to the sliding manifold. This will be done in finite time. After the state reaches the sliding manifold, the error dynamics becomes;

$e_{2}+\lambda e_{1}=0$

The error $e_{1}$ goes to zero asymptotically, i.e., $e_{1} \rightarrow 0$, as $t \rightarrow \infty$.

Now let the sliding mode control law is given by; 
$u=k(t) * \Gamma(s)$

where $\Gamma(s)$ is a discontinuous function, given by:

$\Gamma(s)= \begin{cases}0 & \text { if } s>0 \\ 1 & \text { if } s \leq 0\end{cases}$

and $k(t)$ is the discontinuous gain, with its value adapted according to the following law;

$\dot{\mu}=\rho *|s(x, t)| * \Gamma(s) * \operatorname{sign}(|s(x, t)|-\epsilon)(14)$

After that, $k(t)$ is selected accordingto the following rules;

$k= \begin{cases}\mu & \text { if } 0<\mu<u_{\max } \\ u_{\max } & \text { if } \mu \geq u_{\max } \\ 0 & \text { if } \mu<0\end{cases}$

where $u_{\max }$ is the maximum volumetric flow rate of the hot water value.

\subsection{Maximum Allowable Desired Outlet Cold Water Estimation}

In this section the maximum allowable desired outlet cold water $T_{\text {cor-max }}(t)$ will be estimated. The $T_{\text {cor-max }}(t)$ can be estimated by solving Eq. (1) for the case where steady state conditions hold. That means by equating

$$
\dot{T}_{c o}(t)=\dot{T}_{h o}(t)=0
$$

Then solve for $T_{c o}(t)$ in terms of heat exchanger parameters, hot and cold inlet water temperatures, and $u_{\text {max }}$. According to above, we have:

$$
\begin{aligned}
-k_{1}\left(T_{c o}(t)-T_{h o}(t)\right)+\frac{U_{c}}{V_{c}}\left(T_{c i}(t)-T_{c o}(t)\right) & =0 \\
-k_{2}\left(T_{h o}(t)-T_{c o}(t)\right) & \\
+\frac{1}{V_{h}}\left(T_{h i}(t)-T_{h o}(t)\right) u_{\max } & =0
\end{aligned}
$$

The solution in matrix form is:

$$
\begin{aligned}
& {\left[\begin{array}{c}
T_{\text {cor-max }} \\
T_{h o-\max }
\end{array}\right]=} \\
& {\left[\begin{array}{cc}
\left(k_{1}+\frac{U_{c}}{V_{c}}\right) & -k_{1} \\
-k_{2} & \left(k_{2}+\frac{u_{\max }}{V_{h}}\right)
\end{array}\right]^{-1}\left[\begin{array}{cc}
\frac{U_{c}}{V_{c}} & 0 \\
0 & \frac{u_{\max }}{V_{h}}
\end{array}\right]\left[\begin{array}{l}
T_{c i}(t) \\
T_{h i}(t)
\end{array}\right]}
\end{aligned}
$$

As can be seen from Eq. (16), $T_{h o-\max }$, which is the maximum outlet hot temperature, is estimated too. The numeric values for $T_{\text {cor-max }}$ and $T_{h o-\max }$ will be presented in section (7) below.

\section{State Differentiator Design}

In Eq. (12), the proposed control law assumes that the state variables $z_{1}$ and $z_{2}$ are available. The first state $z_{1}$ is available since it represents the $T_{c o}(t)$, which it is the measured outlet cold water temperature. The second state $z_{2}$ is the time derivative of $z_{1}$. Hence, we need to obtain it using an observer. A robust sliding mode differentiator (SMD) is proposed here to get $z_{2}$ by knowing only $z_{1}$. The sliding mode differentiator is given by [18];

$\left.\begin{array}{l}\sigma=z_{1}-\eta \\ \dot{\eta}=\alpha * \tan ^{-1}\left(\gamma z_{1}\right) \\ \tau \dot{v}+v=\alpha * \tan ^{-1}\left(\gamma z_{1}\right)\end{array}\right\}$

where $\sigma$ is the SMD variable, $\alpha$ and $\rho$ are differentiator parameters. The third equation in (17), $\tau \dot{v}+v=\alpha * \tan ^{-1}\left(\rho z_{1}\right)$, is a low pass filter (LPF) with time constant $\tau$, where the output of the LPF, $v$, is the estimated derivative of $z_{1}$. According to [18], the bound on the steady state estimation error is given by:

$\left|v(t)-z_{2}\right| \leq \frac{2}{\tau \rho} \tan \left(\frac{\pi}{2 \alpha} h\right)$

where $h=\sup _{t}\left|\dot{z}_{1}\right|$. Utilizing the output of the SMD, accordingly; the sliding variable $S$ becomes;

$s=e_{2}+\lambda e_{1}=\left(z_{1}-z_{1 r}\right)+\lambda\left(v-z_{2 r}\right)$

In the following section, the proposed SMC in Eq. (12) with the sliding variable $s$ will be applied to the heat exchanger control system. The block diagram, that depicts the feedback control system for the heat exchanger, is shown below in Fig. (2).

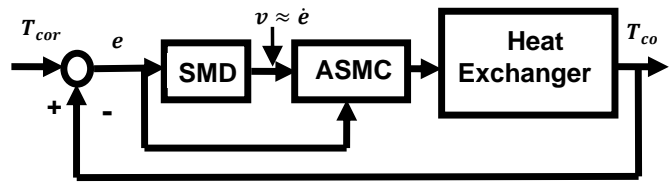

Figure 2: Block Diagram for the ASMC.

\section{Result and Discussion}

In this section the results of the numerical simulations for the heat exchanger control system are presented. The parameters that were used in the simulations are shown in Table 1, while the SMC and SMD parameters, are given in Table 2.

Table 1: Heat exchanger model parameter values [11].

\begin{tabular}{|c|c|}
\hline Parameter & Value \\
\hline$A$ & $0.0672 \mathrm{~m}^{2}$ \\
\hline$C_{p, h}$ & $4180 \mathrm{~J} / \mathrm{kg} \cdot \mathrm{C}^{o}$ \\
\hline$C_{p, c}$ & $4180 \mathrm{~J} / \mathrm{kg} \cdot \mathrm{C}^{o}$ \\
\hline
\end{tabular}




\begin{tabular}{|c|c|}
\hline$\rho_{h}$ & $1000 \mathrm{~kg} / \mathrm{m}^{3}$ \\
\hline$\rho_{c}$ & $1000 \mathrm{~kg} / \mathrm{m}^{3}$ \\
\hline$U$ & $300 \mathrm{~W} / \mathrm{m}^{2} \mathrm{C}^{o}$ \\
\hline$U_{c}$ & $150 \mathrm{~cm}^{3} / \min$ \\
\hline$V_{c}$ & $5.3710^{-4}$ \\
\hline$V_{h}$ & $5.3710^{-4}$ \\
\hline$T_{c i}(t)$ & $20 \mathrm{C}^{o}$ \\
\hline$T_{h i}(t)$ & $80 C^{o}$ \\
\hline$u_{\max }$ & $280 \mathrm{~cm}^{3} / \min$ \\
\hline
\end{tabular}

Table 2: SMC and SMD parameter values.

\begin{tabular}{|c|c|}
\hline SMC Parameters & Value \\
\hline$\lambda$ & 1 \\
\hline$\rho$ & 1 \\
\hline$\epsilon$ & 0.005 \\
\hline SMD Parameters & Value \\
\hline$\alpha$ & 1 \\
\hline$\gamma$ & 100 \\
\hline$\tau$ & 0.05 \\
\hline
\end{tabular}

As it is well known, the discontinuous control induces chattering in control system response. To eliminate chattering, the following approximation is used for $\Gamma(s)$ :

$\tilde{\Gamma}(s)= \begin{cases}0 & \text { if } s>0 \\ \left(\frac{\pi}{2}\right) * \tan ^{-1}(\beta|s|) & \text { if } s \leq 0\end{cases}$

where $\beta=50$. The SMC, that will be used in the present simulations, uses is given by the following control law;

$u=k * \widetilde{\Gamma}(s)$

The SMC and SMD, which will used in the present work, are given in Eq. (21) and Eq. (17) respectively. In addition, from Eq. (16), the maximum allowable desired outlet cold water and the maximum outlet hot temperature are obtained as $T_{\text {cor-max }}=49.2^{\circ}$ and $T_{h o-\max }=64.35^{\circ}$ respectively.

Figure (3) shows the outlet hot and cold water, where the desired outlet cold temperature $T_{\text {cor }}(t)=45^{0}<T_{\text {cor-max }}$. In addition the outlet hot water temperature is plotted, where it can be seen that its value is decreased as a result of transferring heat to the cold water. The volumetric flow rate of the hot water $u(t)$ and the adapted discontinuous gain $k(t)$ are depicted in Fig. (4) and Fig.(5) respectively. The control input $u(t)$ forces the outlet cold temperature $T_{c o}(t)$ to follow the desired temperature in about $300 \mathrm{sec}$. This was done as follow; first the sliding variable $s$ is first regulated to the sliding manifold $s=0$ in about $200 \mathrm{sec}$. (Fig. (6)), after that $T_{c o}(t)$ is asymptotically converges to $T_{\text {cor }}$ as shown in Fig. (3). Finally, the phase plot is shown in Fig. (7), where the state slides along the sliding manifold until it reaches the invariant set around the desired point. The state will stay there for all future time. As in [19], the invariant set size is function to $\beta$, in $\tilde{\Gamma}(s)$, and $u_{\max }$. Increasing $\beta$ and $u_{\max }$ will decrease the steady state error. The steady state error, as can be seen from Fig. (7), is $\mid T_{c o}(t)-$ $T_{\text {cor }}(t) \mid<0.5^{\circ}$.

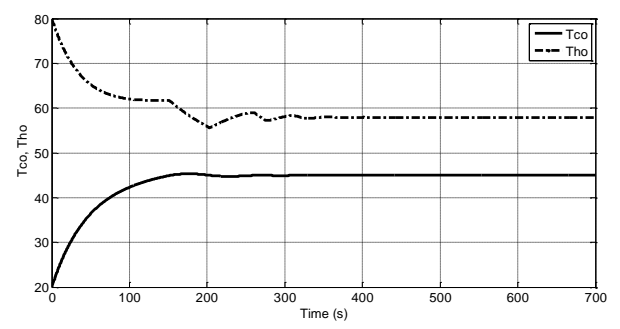

Figure 3: Outlet Cold and Hot Water Temperatures.

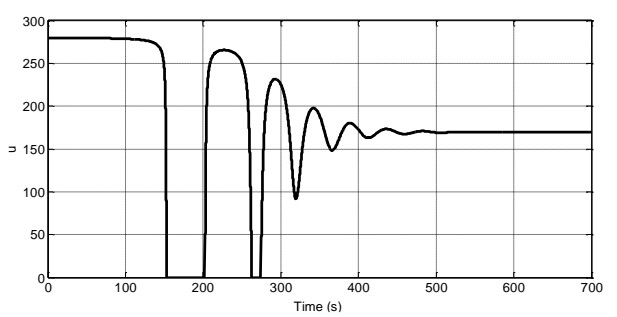

Figure 4: Volumetric Flow Rate of The Hot Water.

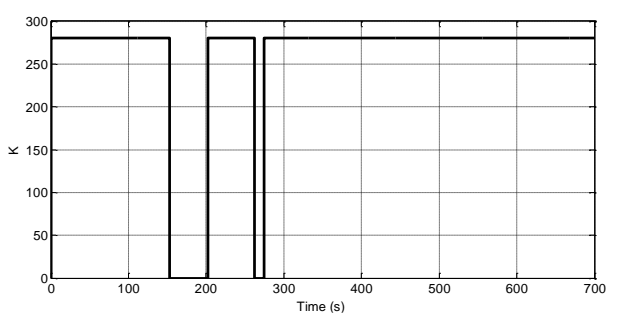

Figure 5: The Adapted Discontinuous Gain $k(t)$.

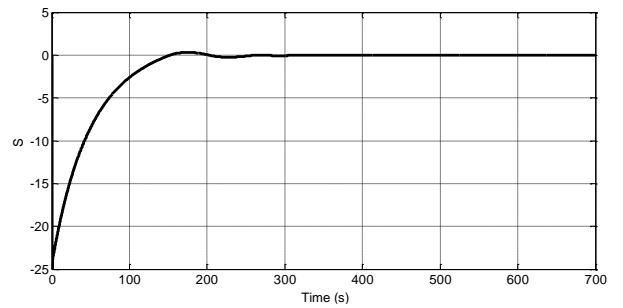

Figure 6: Sliding Variable.

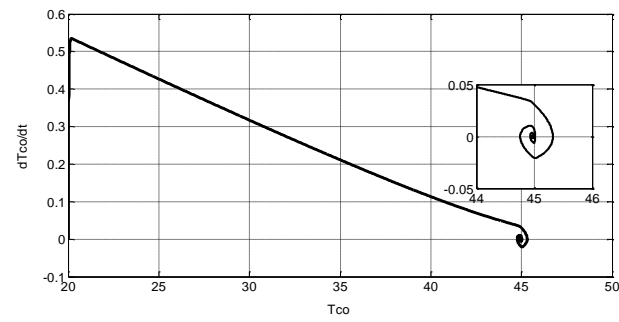

Figure 7: Phase plot.

As stated in section 6, the second state is estimated via SMD. The estimation for the state 
$z_{2}$ is shown in Fig. (8) in addition to the actual value of $z_{2}$. The plotted result in this figure, shows clearly the ability of the SMD in estimating the derivative of $z_{1}$ in presence of the uncertainty in heat exchanger model.

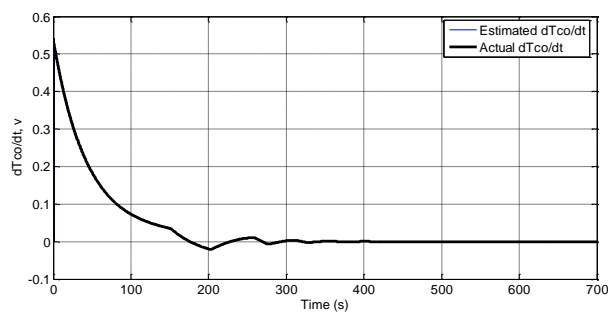

Figure 8: Actual and Estimated Derivative of $T_{c o}$.

Eventually, the simulation was repeated but with the inlet cold water is not constant; instead it is given by $T_{c i}(t)=20+3 * \sin \left(\frac{30 t}{2 \pi}\right)$, where $3 *$ $\sin \left(\frac{30 t}{2 \pi}\right)$ is regarded as a disturbance. The result, which is plotted in Fig. (9), demonstrated clearly the robustness of the proposed SMC, where the $T_{c o}(t)$ converges, as in the previous result, to $45^{\circ}$ with small assolition of amplitude less than $0.2^{\circ}$. Additionally, the robustness was examined again when the some of the heat exchanger parametres are changed. In Fig. (10), the outlet cold and hot water are ploted where the heat transfer coefficient $U$ and the fixed volumetric flow rate of cold water $U_{c}$, which are used in the simulation, are taken equal to $265 \mathrm{~W} / \mathrm{m}^{2} \mathrm{C}^{o}$ and $170 \mathrm{~cm}^{3} / \mathrm{min}$ respectively. As can be seen, the outlet cold water reaches $45^{\circ}$ as in Fig. (3), where $U=300 \mathrm{~W} / \mathrm{m}^{2} \mathrm{C}^{o}$ and $U_{c}=150 \mathrm{~cm}^{3} / \mathrm{min}$.

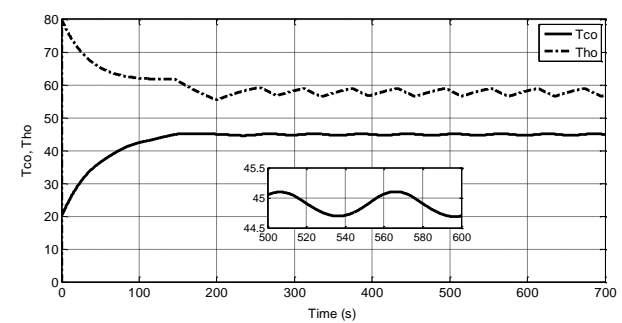

Figure 9: Outlet Cold and Hot Water Temperatures.

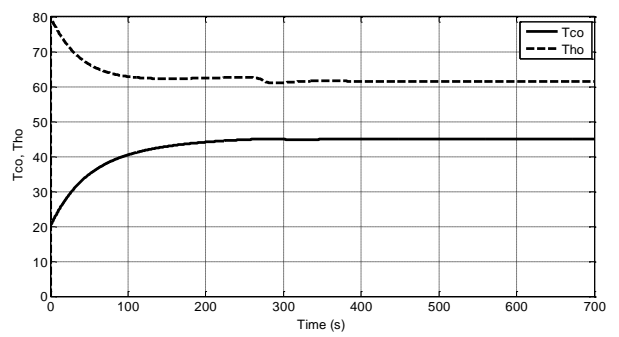

Figure 10: Outlet Cold and Hot Water

Temperatures with Uncertainty in Model Parameters.

\section{Conclusions}

The adaptive sliding mode control was effectively applied to the heat exchanger system. The heat exchanger model has been transformed first to a second order system, considering the outlet cold water $T_{c o}(t)$ as the first state, while its derivative considered as the second state. Utilizing $T_{c o}(t)$ as the only measured or given state, the sliding mode differentiator was used to robustly estimate the second state. Using the measured and the estimated states, the sliding variable, accordingly; was constructed.

The proposed controller was discontinuous, since the control input is a positive value only. To eliminate chattering the proposed SMC was approximated according to Eq. (20).

The simulation results, which have been done using Matlab software, demonstrated the robustness and performance of the proposed SMC, where the $T_{c o}(t)$ forced to follow the desired temperature as shown in Fig. (4) in spite of the uncertainty in heat exchanger model. Additionally, the output of the SMD was compared with actual derivative of $T_{c o}(t)$, and the result showed it was very close to the actual value as was clarified in Fig. (6), and less than the given bound in Eq. (18). Eventually, by disturbing the heat exchanger model with a sinsiodal perturbation to the inlet cold water, and by changing the heat transfer coefficient $U$ and the fixed volumetric flow rate of cold water $U_{c}$, the results, which are plotted in Fig. (9) and Fig. (10), validate the robustness of the proposed controller.

\section{References}

[1] J. Oraveca, M. Bakošová, M. Trafczynskib, A. V. Ckaninov, A. Meszaros, and M. Markowski, "Robust model predictive control and PID control of shell-and-tube heat exchangers" To appear in Energy, Special Issue dedicated to PRES 2017.

[2] Y. Wang, S. You, W. Zheng, H. Zhang, X. Zheng, and Q. Miao, "State space model and robust control of plate heat exchanger for dynamic performance Improvement" To appear in: Applied Thermal Engineering 2017.

[3] M. DulăuP, M. KarolyP, and T. Dulău, "Fluid Temperature Control Using Heat Exchanger" 11th International Conference Interdisciplinarity in Engineering, INTERENG 2017, 5-6 October 2017, Tirgu-Mures, Romania.

[4] V. Bobal, M. Kubalcik, and P. Dosta, "Identification and Self-tuning Predictive Control of Heat Exchanger" 2013 International Conference on Process Control (PC) June 18-21, 2013, Štrbské Pleso, Slovakia.

[5] S. Padhee, Y. B. Khare, and Y. Singh, "Internal Model Based PID Control of Shell 
and Tube Heat Exchanger System" Proceeding of the 2011 IEEE Students' Technology Symposium 14-16 January, 2011, IIT Kharagpur.

[6] A. Zavala-Rio, C.M. Astorga-Zaragoza, and O. Hernandez-Gonzalez, "Bounded positive control for double-pipe heat exchangers" Control Engineering Practice 17 (2009) 136- 145 .

[7] J. Alvarez-Ramirez, I. Cervantes, and R. Femat, "Robust Controllers for a Heat Exchanger" Ind. Eng. Chem. Res. 1997, 36, 382-388.

[8] P. Chalupa, V. Bobál, M. Kubalčík, and J. Novák, "Adaptive Predictive Control of Through-flow Heat Exchanger" 18th Mediterranean Conference on Control \& Automation Congress Palace Hotel, Marrakech, Morocco June 23-25, 2010.

[9] E. Lavretsky, and K. A. Wise, Robust And Adaptive Control, Springer Science \& Business Media 2013.

[10] F. Plestan, Y. Shtessel, V. Bregeault., and A. Poznyak, "New Methodologies For Adaptive Sliding Mode Control" International Journal of Control, vol. 83no. 9, pp. 1907-1919, July 2010.

[11] N. B. Almutairi, and M, Zribi, "Control of a Plate Heat Exchanger Using the Terminal Sliding Mode Technique" Industrial \& Engineering Chemistry Research, 51, 4610-4623, 2012.

[12]Z. Jian, S. He-xu, and Z. Jiang-tao, "Application of Adaptive Fuzzy Slidingmode Controller for Heat Exchanger System in District Heating" 2008 International Conference on Intelligent Computation Technology and Automation.
[13] S. Rao, and V. Utkin, "Sliding Mode Control of One-Dimensional Heat Exchange Processes" Proceedings of the 2006 International Workshop on Variable Structure Systems Alghero, Italy, June 5-7, 2006.

[14] V. Utkin, J. Guldner, and J. Shi, Sliding Mode Control In Electro-Mechanical Systems, Taylor \& Francis Group, LLC, 2nd edition, 2009.

[15] V. I. Utkin, and A. S. Poznyak, Adaptive Sliding Mode Control, in B. Bandyopadhyay, S. Janardhanan, and S. K. Spurgeon (Eds.), Advances in sliding mode control: concept, theory and implementation, Springer, New York, pp.22-53, 2013.

[16] S. A. Al-Samarraie, and M. M. Salih, "Adaptive Sliding Mode Controller for Servo Actuator System with Friction" Journal of Engineering, Number 1, Volume 23, January 2017.

[17] S. A. Al-Samarraie, B. F. Midhat and R. A. Bahaa Al-Deen, " Adaptive Sliding Mode Control for Magnetic levitation system" AlNahrain Journal for Engineering Sciences (NJES) Vol.21 No.2, pp.266-274, 2018.

[18] M. H. Mishary, Sliding Mode Observer for States and Perturbation, M.Sc. Thesis Submitted to the Department of Control and Systems Engineering at University of Technology, Oct. 2016.

[19] S. A. Al-Samarraie, "Invariant Sets In Sliding Mode Control Theory with Application to Servo Actuator System with Friction" WSEAS Transection on Systems and Control, Issue 2, Volume 8. April, 2013.

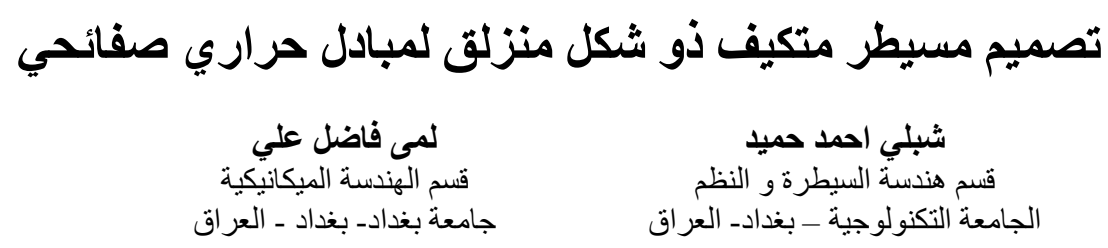

الخلاصة

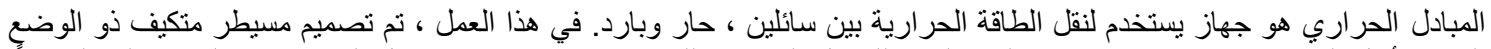

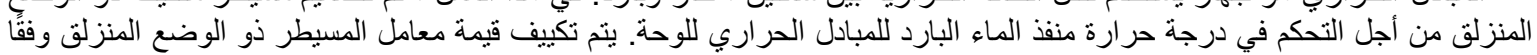

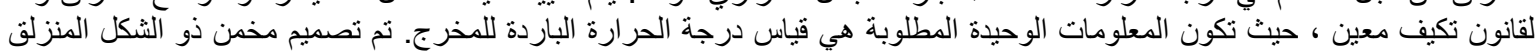

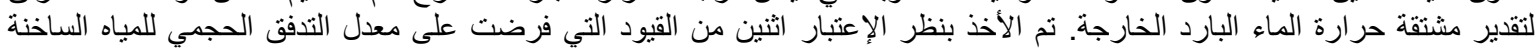

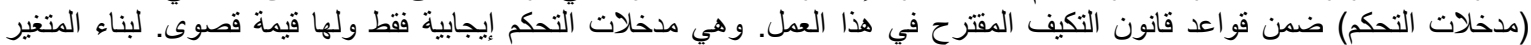

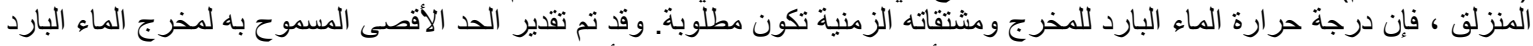

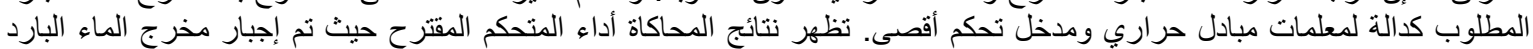

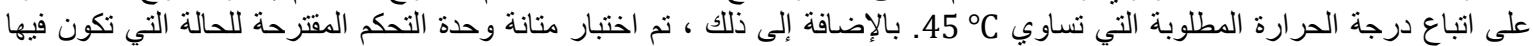

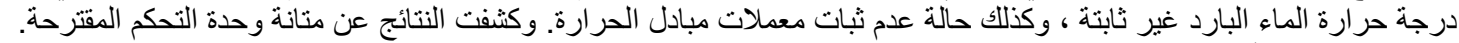

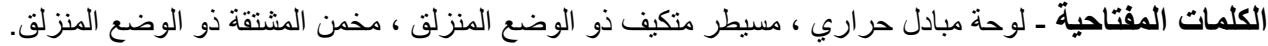

